\title{
Vacuum-assisted microwave drying characteristics of green bell pepper
}

\author{
ViveK Kumar $^{a^{*}}$ AND Shanker L. Shrivastava ${ }^{\mathrm{a}}$ \\ ${ }^{a}$ Department of Agricultural and Food Engineering, Indian Institute of Technology, Kharagpur, West Bengal; \\ India-721302 \\ ${ }^{*}$ Corresponding author \\ vivekk.iitkgp@gmail.com \\ TEL: $+91-9734982094$
}

Received: 24 September 2016; Published online: 18 April 2017

\begin{abstract}
Chopped green bell pepper pieces were blanched $\left(95{ }^{\circ} \mathrm{C}, 5 \mathrm{~min}\right)$ and chemically pretreated $(1 \%$ potassium metabisulphite solution, $25 \mathrm{~min}$ at room temperature) before drying in hot air dryer (HAD) at various temperature ranges $\left(60-80{ }^{\circ} \mathrm{C}\right)$. Three vacuum levels $(200,400,600 \mathrm{~mm} \mathrm{Hg})$ and microwave power levels $(100,200,300 \mathrm{~W})$ were also used to dry green bell pepper samples in a vacuum-assisted microwave (VAM) $(2.45 \mathrm{GHz}, 0.8 \mathrm{~kW})$ dryer. VAM drying methods offered a maximum reduction by four to five times in drying time as compared to that in HAD. The logarithmic model was found to have the best fit based on high $\mathrm{R}^{2}$ and small values of reduced $\chi^{2}$ and RMSE. VAM method has higher values for effective moisture diffusivity $\left(\mathrm{D}_{\text {eff }}\right)$ and lower values for activation energy $\left(\mathrm{E}_{a}\right)$, in comparison to the HAD method.
\end{abstract}

Keywords: Green bell pepper; Activation energy; Drying kinetics; Effective moisture diffusivity; Logarithmic model; Vacuum-assisted microwave drying

\section{Introduction}

Green bell peppers (Capsicum annum L.) are a non-pungent pepper variety of the genus Capsicum of Solanaceae family. They are thickfleshed and have unique heart shape, 7 to $10 \mathrm{~cm}$ in length and 5 to $7 \mathrm{~cm}$ wide (medium, elongate) and are consumed green or ripe in salads, soups, pasta, stews, pickles, tarts, risottos, and relishes. Like other vegetables, they are quite perishable, facing high losses due to storage problems, and inappropriate processing technologies. The price of bell peppers varies widely in the market, declining during peak season and increasing in lean season during a year. To permit the availability of the product all-round the year and prevent post-harvest losses, drying is one of the important preservation methods. Dried bell peppers are used in food mixtures, salad dressings, instant soups, frozen pizzas and many other convenience foods. Drying stabilizes the fresh product as it lowers the water activity, thus prolonging the keeping quality, reducing the storage volume and decreasing transport costs (Govindarajan \& Salzer, 1985).

Choosing an appropriate drying method is an important criterion as bell peppers are very sensitive to temperature. Sun and solar drying methods have been suggested for green bell peppers (Tunde-Akintunde \& Ogunlakin, 2011), but mechanical drying such as tray and conventional hot air drying methods have been mainly used. Prolonged drying time and surface overheating in conventional hot-air drying cause colour darkening, flavour loss and a decrease in rehydration ability. Freeze drying can be an alterna- 


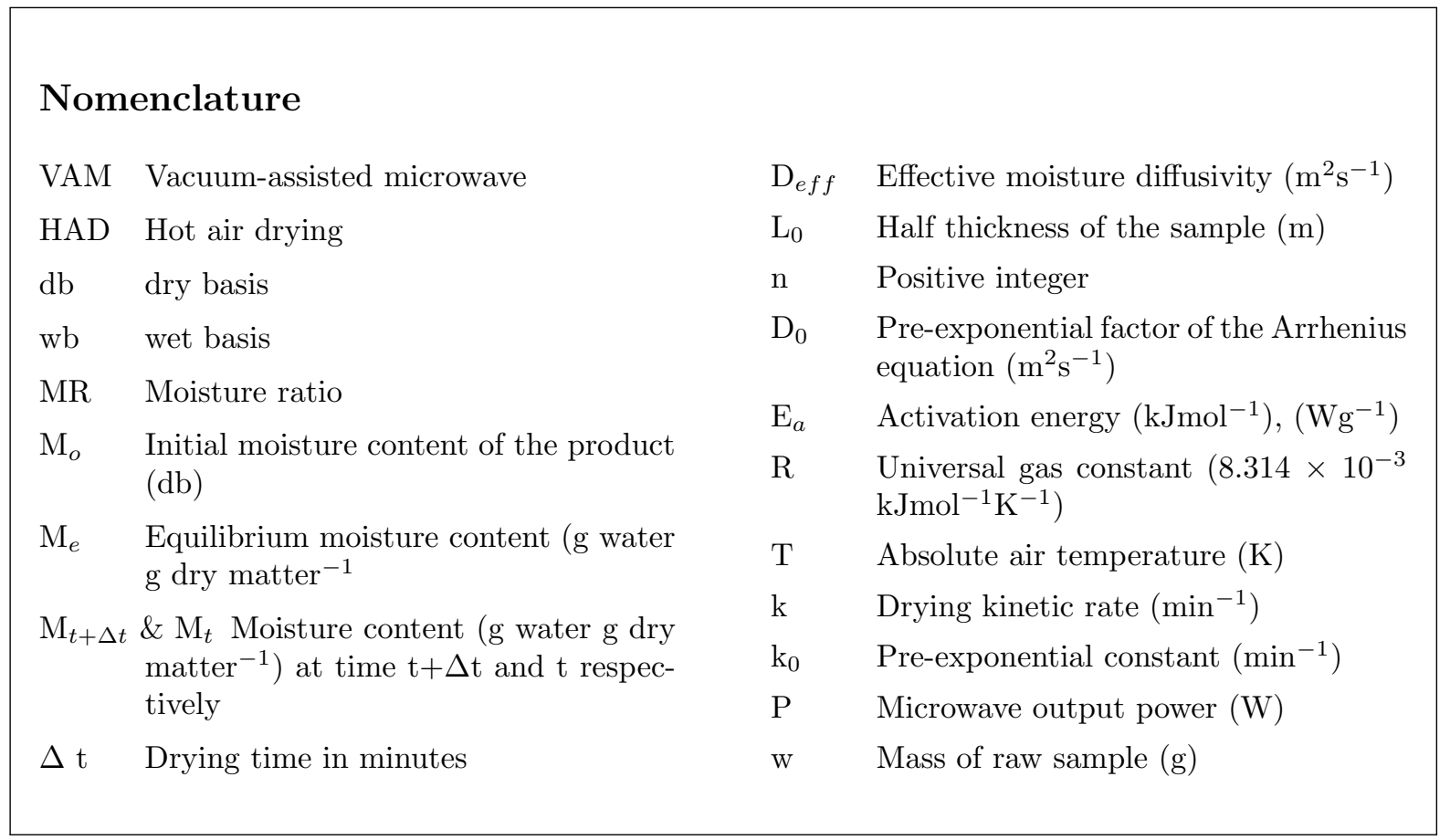

tive method, where the end product has better colour, flavour, and rehydration ability but has the limitation of high cost and longer processing time. Vacuum drying is yet another method used for heat sensitive fruits and vegetables. However, due to the ineffectiveness of convection at low pressure, which causes difficulty in the transfer of heat energy to the sample load and the higher installation and operating costs (Woodroof, 2012), its use has limited advantages. The desire to prevent significant quality loss and to achieve fast and effective dehydration has resulted in increasing use of microwave heating for food drying (Giri \& Prasad, 2007). Unlike other drying methods, microwave drying is rapid, more uniform and energy efficient as heat is generated from the inner section of food and both heat and mass transfer in the same direction.

In recent years, vacuum-assisted microwave (VAM) drying has been investigated as a potential method for obtaining high quality dried food products, including fruits, vegetables, and grains (Giri \& Prasad, 2007). VAM drying combines the advantages of both: low-temperature evaporation of moisture with faster moisture removal by vacuum and rapid volumetric heating by microwave (Cui, Xu, \& Sun, 2003), thus increasing the overall product quality and energy efficiency. Various investigations have been carried out on VAM drying, but very little information is available regarding the drying kinetics of green bell peppers.

Drying kinetics define the moisture removal process and its dependence on the process variables like drying condition, types of dryer and characteristics of the material to be dried (Guine \& Fernandes, 2006). The effect of vacuum in microwave drying operation is system specific and for successful design and operation of an industrial VAM drying system, knowledge of the drying characteristics of the material to be dried under a range of condition is vital. Very little literature focuses on modelling of VAM dried food products. The process of coupled heat and moisture transfer during VAM drying of a soluble food concentrate has been described by Lian, Harris, Evans, and Warboys (1997), where they considered the moisture transfer as a combination of simultaneous water (liquid) and vapor transfer. Kiranoudis, Tsami, and Maroulis 
(1997) studied the mathematical model of the microwave vacuum drying kinetics of some fruits. An empirical mass transfer model, involving a basic parameter of phenomenological nature, was used, and the influence of process variables was examined by linking them to the drying constant. In modelling of drying systems, the biological changes within the food are the main cause of concern and should be taken into consideration when modelling material moisture content and temperature profile of a drying system (Mujumdar, 1980).

The lack of published work on the VAM drying kinetics of green bell peppers, either regarding empirical models or regarding diffusivity model explains the interest in the present work. The aim of the present work was to investigate vacuum-assisted microwave drying characteristics of green bell pepper and to compare with hot air drying with respect to drying kinetics.

\section{Materials and Methods}

\subsection{Drying preparation}

Fresh green bell peppers were procured from the local market of Kharagpur, West Bengal, India. The sorted bell peppers were washed in cold water and cut with knives into approximate sizes of $40 \mathrm{~mm} \times 40 \mathrm{~mm}$ with a thickness of $4 \pm 0.5 \mathrm{~mm}$. Initial moisture content before drying was observed to be in the range of 11.50 to $15.71 \mathrm{~kg}$ of water $\mathrm{kg}$ of dry matter ${ }^{-1}$. After cutting, they were blanched with hot water at $95{ }^{\circ} \mathrm{C}$ for $5 \mathrm{~min}$ with a ratio of bell pepper pieces to blanching water of 1:5. Pretreatment was carried out by dipping fresh bell pepper pieces in a solution of $1 \%$ potassium metabisulphite solution for $25 \mathrm{~min}$ at room temperature. The ratio of bell pepper to pretreatment solution was similar to the water blanching method. Untreated, blanched and chemically pretreated samples were spread uniformly in a single thin layer in a hot-air dryer. For VAM drying, cut samples were taken without any treatments. The levels of each variable were selected by earlier research work and trial experiments (Jayaraman, Gopinathan, Pitchamuthu, \& Vijayaraghavan, 1982; Wesley, Chakraverty, \& Sukumaran, 2002).

\section{$2.2 \quad$ Experimental apparatus}

\section{Hot-air drying system}

The hot-air dryer (SD Instruments Pvt. Ltd, Kolkata, West Bengal, India) (Figure 1), was used for drying of green bell pepper. Heaters, heating control units, drying chambers, blowers, air flow duct, measurement sensors, and control panel, were the main components of the dryer. In total, three heaters were used comprising two booster heaters and one control heater of 3500 $\mathrm{kW}$. All interior parts of the hot air dryer including trays were made of stainless steel - 304 and 5 $\mathrm{cm}$ thick insulation was provided on all sides of the dryer. The temperature of the heated air was displayed on the control panel, which was measured by a Pt-100 sensor (Platinum resistance thermometers, Silicon Pvt. Ltd., Mumbai, India).

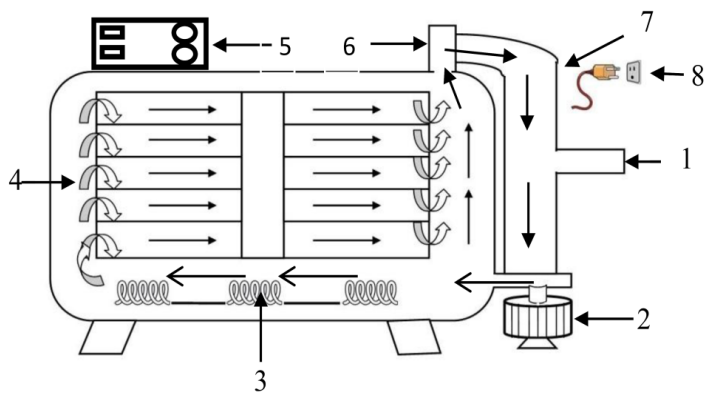

Figure 1: Schematic diagram of hot air dryer (1) Inlet air; (2) Blower; (3) Heater; (4) Drying cabinet with removable trays; (5) Control panel; (6) Exhaust air outlet; (7) Air passage line; (8) Power plug

\section{Vacuum-assisted microwave drying system}

The experimental VAM drying setup (Figure 2 ) consisted of a microwave oven $(0.8 \mathrm{~kW})$ (Model: Samsung), a variable voltage transformer (variac), a glass vacuum desiccator, hose pipe, condenser and pressure gauge.

The power output of the microwave oven was modified with the help of the variac. The glass 
vacuum desiccator containing the sample was put inside a microwave oven, and the lid of it was attached to a vacuum pump through a hose pipe. The vacuum was monitored by a vacuum gauge and controlled by a pressure regulator. A condenser was also attached to the hose pipe for condensing the water vapour at low temperature.

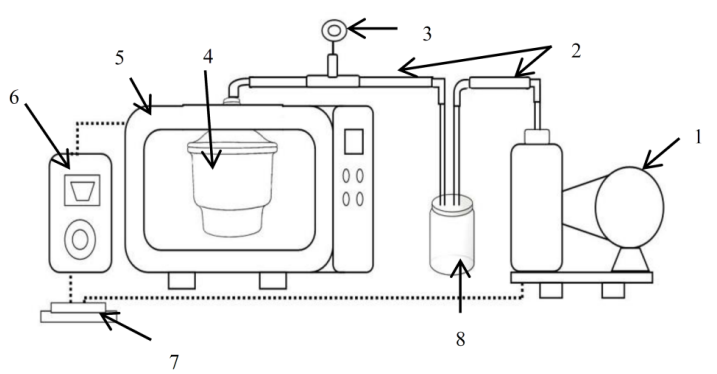

Figure 2: Schematic diagram of vacuum-assisted microwave dryer (1) Vacuum pump; (2) Hose pipe; (3) Pressure gauge; (4) Glass vacuum desiccator; (5) Microwave oven; (6) Control panel; (7) Electrical board; (8) Condenser

\section{Experimental procedure}

To achieve steady state temperature conditions during each experimental run, the hot-air dryer was started one hour before the actual experiment. Untreated, chemically pretreated and blanched green bell pepper samples were weighed and spread uniformly in a single layer over the tray. Drying experiments were performed at 60 , $65,70,75$ and $80{ }^{\circ} \mathrm{C}$. Relative humidity of the ambient air changed in between $20 \%$ to $23 \%$. For VAM drying experiments, three levels of vacuum $(200,400,600 \mathrm{~mm} \mathrm{Hg})$ and microwave power $(100,200,300 \mathrm{~W})$ were used to dry samples of green bell pepper in a vacuum assisted microwave $(2.45 \mathrm{GHz}, 0.8 \mathrm{~kW})$ dryer. The glass desiccator containing freshly cut green bell pepper sample was put inside the microwave oven and covered with the lid. The desiccator was connected to the vacuum pump through the hose pipe with the condenser in between. The vacuum was maintained inside the desiccator with the help of pressure regulator valve. Once the vacuum was achieved, the microwave oven was switched on, and various power levels were set with the help of voltage variac. The weight of the samples was periodically recorded after switching off the microwave oven and releasing the vacuum. The weight loss of samples in both the drying methods was measured using analytical balance (Sartorius TE 153S, Sartorius Weighing India Pvt. Ltd., Bangalore, Karnataka, India) in a range of $0-300 \mathrm{~g}( \pm 0.001 \mathrm{~g})$ during drying at 5 min intervals for the first half hour, then $10 \mathrm{~min}$ for the next hour, followed by 15 min interval for the next 1.5 hours and finally at every half hour interval until it reached 0.06 to $0.07 \mathrm{~kg}$ of water $\mathrm{kg}$ of dry matter ${ }^{-1}$.

In both the drying methods i.e. HAD and VAM drying, the whole process of recording the data and placing the sample back in the dryer took almost 20 seconds. The drying process was continued for a given set of drying conditions until two successive observations of the weight of the sample were same. The final dried sample was cooled to normal temperature in a desiccator containing silica gel and then packed air-tight in low-density polyethylene pouches by heat sealing. Each experiment was performed in triplicates.

\subsection{Theoretical considerations}

\section{Modelling of the thin layer drying curves}

For studying the drying characteristics of green bell pepper, it is very important to model the drying behaviour effectively. The data obtained at different drying temperatures were fitted into three commonly used thin layer drying models, as listed in Table 1.

In single layer drying experiments, the moisture ratio of green bell pepper was calculated using the following Eq. 1.

$$
M R=\frac{M_{t}-M_{e}}{M_{o}-M_{e}}
$$

The drying rates of green bell pepper were calculated using Eq. 2.

$$
\text { Drying Rate }=\frac{M_{t+\Delta t}-M_{t}}{\Delta t}
$$


Where, $M_{o}$ is the initial moisture content of the product $(\mathrm{db}), M_{e}$ is the equilibrium moisture content (g water g dry matter ${ }^{-1}$ ), $M_{t+\Delta t}$, and $M_{t}$, are the moisture content (g water $\mathrm{g}$ dry matter $^{-1}$ ) at time $t+\Delta t$ and $t$ respectively, and $\Delta t$ is the drying time in minutes. Over a long period, convective drying values for $M e$ stands negligible (Diamante \& Munro, 1991; Giri \& Prasad, 2007; Tulek, 2011). Thus, Eq. 1 can be simplified as Eq. 3.

$$
M R=\frac{M_{t}}{M_{o}}
$$

\section{Correlation coefficients and error analysis}

To evaluate the goodness of fit of the mathematical models, correlation coefficient $\left(R^{2}\right)$, reduced chi-square $\left(\chi^{2}\right)$ and root mean square error $(R M S E)$ were calculated. The best model describing the thin layer drying characteristics of green bell pepper was chosen as the one with lower $\chi^{2}$ and $R M S E$ and higher $R^{2}$ values. These parameters can be calculated as follows:

$$
R^{2}=\frac{S S_{\text {Total }}-S S_{\text {Error }}}{S S_{\text {Total }}}
$$

Where,

$$
\begin{gathered}
S S_{\text {Total }}=\sum_{i=1}^{N}\left(M R_{\text {exp }, i}-M R_{\text {pre }, i}\right)^{2} \\
S S_{\text {Error }}=\sum_{i=1}^{N}\left(M R_{\text {exp }, i}-M R_{\text {pre }, i}\right)^{2} \\
R M S E=\sqrt{\frac{\sum_{i=1}^{N}\left(M R_{\text {exp }, i}-M R_{\text {pre }, i}\right)^{2}}{N}} \\
\chi^{2}=\frac{\sum_{i=1}^{N}\left(M R_{\text {exp }, i}-M R_{\text {pre }, i}\right)^{2}}{N-Z}
\end{gathered}
$$

Where, $M R_{\text {exp }, i}$, is the $i^{t h}$ experimental moisture ratio, $M R_{\text {pre, } i}$, is the $i^{\text {th }}$ predicted moisture ratio, $N$ is the total number of observations and $Z$ is the number of constants.

\section{Calculation of effective moisture diffusivities}

The drying characteristics of biological products in the falling rate period are described by using Fick's diffusion equation. Assuming a constant moisture diffusivity, infinite slab geometry, and uniform initial moisture distribution in the food sample, Eq. 9 can be used to predict the moisture diffusion.

$$
M R=\frac{8}{\pi^{2}} \sum_{n=0}^{\infty} \frac{1}{2 n+1} e^{\left(-\frac{(2 n+1)^{2} \pi^{2} D_{e f f^{t}}}{4 L_{0}^{2}}\right)}
$$

Where, $D_{\text {eff }}$ is the effective moisture diffusivity $\left(\mathrm{m}^{2} \mathrm{~s}^{-1}\right), \mathrm{t}$ is the drying time (min), $L_{o}$ is half the thickness of slab $(\mathrm{m})$, and $n$ is a positive integer. For long drying period, Eq. 9 can be further simplified to only the first term of series. Thus, Eq. 10 is written in a logarithmic form as follows

$$
\operatorname{Ln}(M R)=\operatorname{Ln} \frac{8}{\pi^{2}}-\frac{\pi^{2} D_{e f f} t}{4 L_{0}^{2}}
$$

The effective moisture diffusivity is obtained by plotting experimental drying data in terms of $l n$ $(M R)$ vs. drying time (Eq. 10) because the plot gives a straight line with a slope as follows (Wang et al., 2007).

$$
\text { Slope }=-\frac{\pi^{2} D_{e f f}}{4 L_{0}^{2}}
$$

\section{Calculation of activation energy}

The temperature dependence of the effective diffusivity has been shown to follow an Arrheniustype relationship (Eq. 12) (Saravacos \& Maroulis, 2001; Simal, Mulet, Tarrazo, \& Rossello, 1996).

$$
D_{e f f}=D_{o} e^{\left(-\frac{E_{a}}{R T}\right)}
$$

Where, $D_{o}$ is the pre-exponential factor of the Arrhenius equation $\left(\mathrm{m}^{2} \mathrm{~s}^{-1}\right), E_{a}$ is the activation energy $\left(\mathrm{kJmol}^{-1}\right), R$ is the universal gas constant $\left(8.314 \times 10^{-3} \mathrm{kJmol}^{-1} \mathrm{~K}^{-1}\right)$, and $T$ is the absolute air temperature $(\mathrm{K})$. The activation energy was determined from the slope of the Arrhenius plot, $\ln \left(D_{e f f}\right)$ vs. $T^{-1}$

As the temperature was not precisely measurable 
Table 1: Thin layer drying models used for vacuum drying characteristics of green bell pepper

\begin{tabular}{lll}
\hline Model Name & Expression & Reference \\
\hline Lewis & $M R=e^{-k t}$ & Lewis (1921) \\
Henderson and Pabis Model & $M R=a \cdot e^{-k t}$ & Henderson and Pabis (1961) \\
Logarithmic Model & $M R=a \cdot e^{-k t}+c$ & Toğrul and Pehlivan (2002) \\
\hline
\end{tabular}

inside the microwave drier, the activation energy was found from the revised Arrhenius equation. In the first method, it was assumed as being related to the drying kinetic rate $(k)$ and the ratio of sample weight to microwave output power $(w / P)$ instead of air temperature. Then Eq. 13 could be effectively used (Dadali, Apar, \& Ozbek, 2007) as follows:

$$
k=k_{o} e^{\left(-\frac{E_{a} W}{P}\right)}
$$

Where, $k$ is the drying rate constant obtained by using the best model $\left(\min ^{-1}\right), k_{o}$ is the preexponential constant $\left(\mathrm{min}^{-1}\right)$. In the second method, the correlation between effective diffusion coefficient and $(w / P)$ was used for calculation of the activation energy.

$$
D_{e f f}=D_{o} e^{\left(-\frac{E_{a} W}{P}\right)}
$$

Where, $E_{a}$ is the activation energy $\left(\mathrm{Wg}^{-1}\right), w$ is the mass of raw sample $(\mathrm{g})$, and $D_{o}$ is the preexponential factor $\left(\mathrm{m}^{2} \mathrm{~s}^{-1}\right)$.

\section{Results and Discussion}

\subsection{Moisture content}

For all experiments, the initial moisture content before drying was observed to be in the range of 11.50 to $15.71 \mathrm{~kg}$ of water $\mathrm{kg}$ of dry matter ${ }^{-1}$. The relationship between moisture content and drying time for HAD and VAM dried samples are shown in Figures 3, 4 and 5, and exhibited a non-linear decrease of moisture with drying time. Figure 3 shows the relationship between moisture content and drying time for HAD samples at 60 ${ }^{\circ} \mathrm{C}$ for various treatments. Figures 4 and 5 show the effect of power level and vacuum level respectively on the graph between moisture content and drying time for VAM dried samples.
Initially, moisture decreased rapidly, and then the rate of decrease slowed down considerably as expected. The drying time varied with drying temperature in HAD and with varying power, and vacuum level in case of VAM drying.

The final moisture content varied from 0.06 to $0.07 \mathrm{~kg}$ of water $\mathrm{kg}$ of dry matter ${ }^{-1}$. Figures 4 and 5 further show the effect of microwave power and vacuum on drying time during VAM drying. From these graphs, it was evident that microwave power had more pronounced effect on drying time as compared to the system vacuum. For a given microwave power of $100 \mathrm{~W}$, the drying time decreased by $40 \%$ from value of $450 \mathrm{~min}$ at $200 \mathrm{~mm}$ $\mathrm{Hg}$ to $250 \mathrm{~min}$ at $600 \mathrm{~mm} \mathrm{Hg}$. At a higher power level of $300 \mathrm{~W}$, the system vacuum had no effect on the drying time, being $75 \mathrm{~min}$ at all system vacuum levels. At a vacuum level of $200 \mathrm{~mm} \mathrm{Hg}$, the drying time decreased by $83 \%$ from the value of $450 \mathrm{~min}$ at $100 \mathrm{~W}$ to $75 \mathrm{~min}$ at $300 \mathrm{~W}$. Similarly, at $400 \mathrm{~mm} \mathrm{Hg}$ and $600 \mathrm{~mm} \mathrm{Hg}$, there was a decrease of $78 \%$ and $70 \%$ in drying time, respectively. It was evident from Figure 7 that the drying time decreased with the increase in power output. However, the effect of system pressure on drying time was not as significant as that of microwave power.

As can be seen in Figures 6 and 7, the drying time ranged from $660 \mathrm{~min}$ (untreated sample at $60{ }^{\circ} \mathrm{C}$ ) to $360 \mathrm{~min}$ (blanched sample at $80{ }^{\circ} \mathrm{C}$ ) in case of HAD and $75 \mathrm{~min}(300 \mathrm{~W})$ to $450 \mathrm{~min}$ (100 W) in case of VAM drying, being generally lower at higher drying temperatures and power levels. The decrease in total drying time with an increase in drying air temperature and the power level was due to the increase in the water vapour pressure within the samples which increased the migration of moisture from inside of the product to its surface. In HAD, the decrease in relative humidity of drying air at a higher temper- 
ature also increased its moisture carrying capacity. The results are in agreement with the work of earlier researchers (Bhattacharya, Srivastav, \& Mishra, 2015; Chauhan \& Srivastava, 2009; Giri \& Prasad, 2007). VAM drying methods offered a maximum reduction by four to five times in drying time as compared to that in HAD.

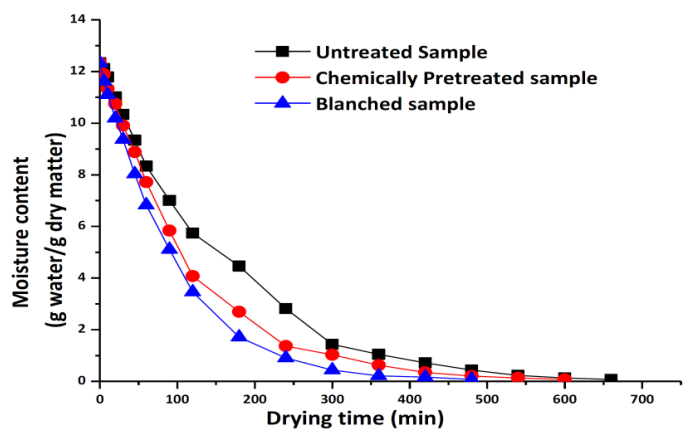

Figure 3: Drying behaviour of untreated, chemically pretreated and blanched sample at $60{ }^{\circ} \mathrm{C}$

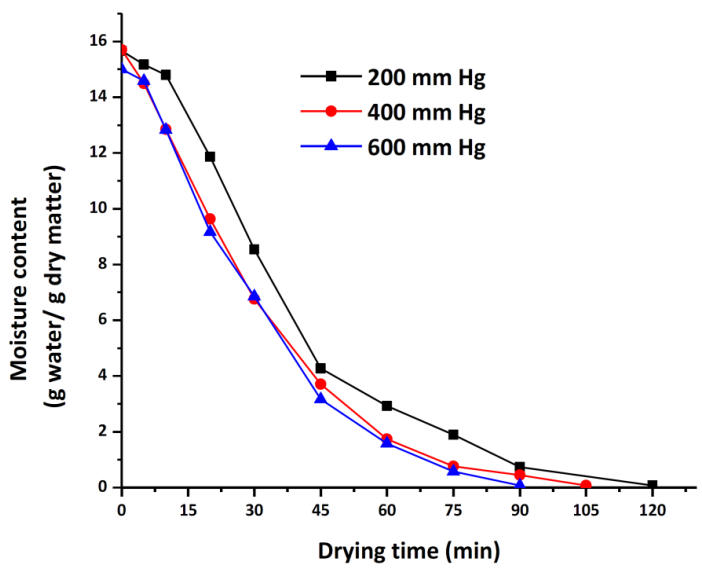

Figure 4: Variation in moisture content of green bell pepper with drying time at varying vacuum levels at $200 \mathrm{~W}$

\subsection{Drying rate}

The variation in drying rate of untreated, chemically pretreated and blanched sample with mois-

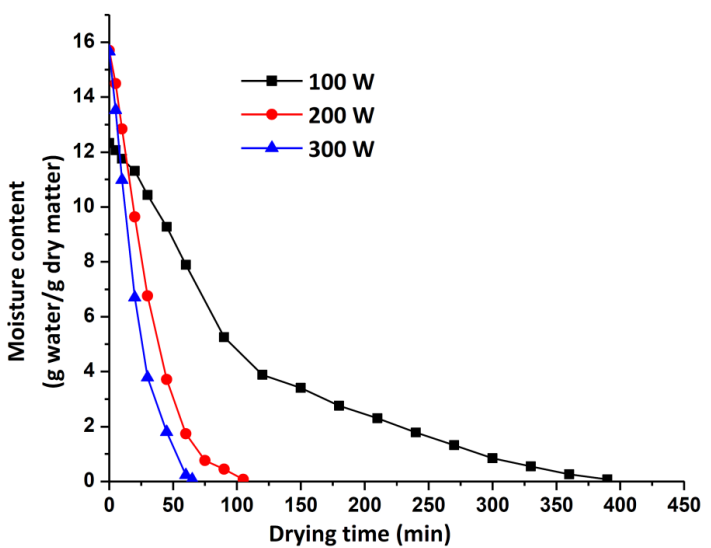

Figure 5: Variation in moisture content of green bell pepper with drying time at varying power levels at $400 \mathrm{~mm} \mathrm{Hg}$

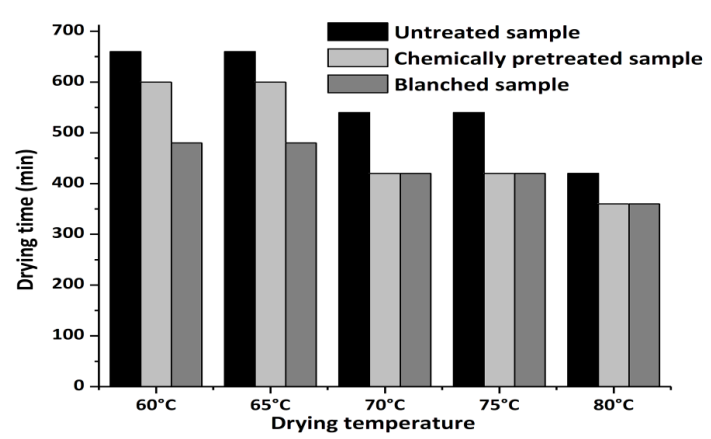

Figure 6: Drying time of green bell pepper at different temperatures in HAD

ture content, at $70{ }^{\circ} \mathrm{C}$ is depicted in Figure 8 . Higher drying rates were observed at the beginning of drying process when the moisture content of the product was higher. No constant rate period was found and drying mostly took place in the falling rate period for all the cases. This indicated that the overall drying process was being governed by internal diffusion phenomena.

Figure 9 shows the variation in drying rate with moisture content for different microwave power levels at $400 \mathrm{~mm} \mathrm{Hg}$. Constant rate drying was not found in any of the microwave power and system vacuum combinations. High moisture foods usually have a constant rate of drying, but this 


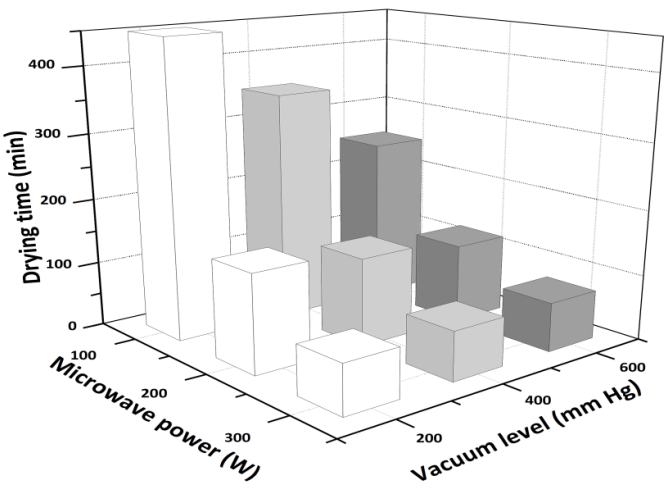

Figure 7: Drying time of green bell pepper at different microwave power and vacuum levels

was not observed in the present study of green bell pepper. The probable reason may have been instant heating in the thin layer arrangement and very rapid heating by microwaves. As evident from Figure 9, the drying rate was higher at higher microwave power. The influence of power on drying rate was markedly higher when the moisture was higher. The same trends were also seen in the work of Giri and Prasad (2007), and Chauhan and Srivastava (2009). There was no significant difference in the drying rates among different power levels after moisture content reached value less than 3.0 gram water gram dry matter ${ }^{-1}$. This indicated the significance of internal resistance to mass transfer at low water content in green bell pepper. Since the amount of microwave energy absorbed by the food material is dependent on its dielectric properties and electric field strength (Mudgett, 1990), the material will absorb more microwave power, and heating is faster at high moisture content. The values of dielectric constant and loss factors are higher at a higher moister content of the food material. With drying of food material, its moisture content decreases and thus microwave energy absorption decreases leading to falling in the drying rate at the later stage of drying (Khraisheh, 1996; Sharma \& Prasad, 2001). Microwave heating under vacuum resulted in large increase in drying rates (almost four to five fold) as compared to hot-air drying throughout the drying process.

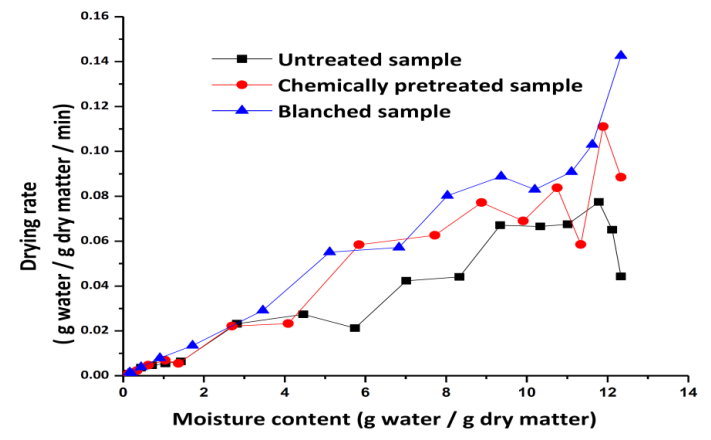

Figure 8: Variation in drying rate with moisture content for untreated, chemically pretreated and blanched sample of green bell pepper at $70{ }^{\circ} \mathrm{C}$

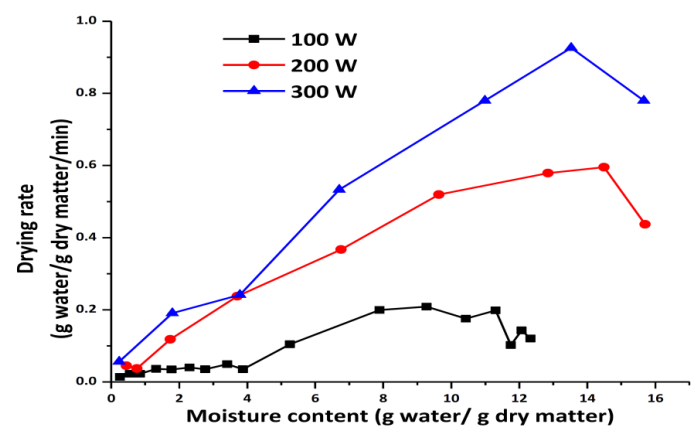

Figure 9: Variation in drying rate with moisture content for different microwave powers at $400 \mathrm{~mm} \mathrm{Hg}$

\subsection{Validity of models}

Various drying models (Table 1) were fitted to the HAD and VAM dried experimental data (MR vs. time) in their linearized form using regression techniques. The model coefficients for all the three models were estimated by a non-linear regression technique using software Origin Pro 8.5.0 (Origin Lab Corporation, Northampton, Massachusetts, USA). The comparison of the applicability of all three models was done on the basis of the coefficient of determination $\left(R^{2}\right)$, reduced chi-square $\left(\chi^{2}\right)$ and root mean square error $(R M S E)$. The goodness of fit of the models is characterized by the highest value of $R^{2}$, and 
lowest value of $\chi^{2}$ as well as $R M S E$. The statistical results of the different models, including the comparison criteria, used to evaluate goodness of fit, viz. the values of $\mathrm{R}^{2}, \chi^{2}$ and $R M S E$ are presented in Table 2. On the basis of the highest value of $\mathrm{R}^{2}$ and lowest values of $\chi^{2}$ and $R M S E$ having values of $0.9995,0.000066,0.0008$ and $0.9998,0.0007,0.0036$ for HAD and VAM dried samples respectively, the logarithmic model was found to be most satisfactory. The logarithmic model could be used to estimate the moisture content of green bell pepper at any time during the drying process at different temperatures with an acceptable accuracy. It was observed that $R^{2}$ value ranged from 0.9861 to 0.9988 for HAD method and 0.9502 to 0.9926 for VAM dried samples. The value of RMSE ranged from 0.00233 to 0.0192 for HAD samples and 0.02255 to 0.21436 for VAM dried samples whereas the value of $\chi^{2}$ ranged from 0.000066 to 0.001750 for HAD and from 0.0007 to 0.12297 for VAM dried samples. Validation of the selected model was made comparing the computed and measured values of moisture contents in all the drying runs as shown in Figures 10 and 11. It was observed that consistency of fitting the drying data into the logarithmic model was very good for all the experimental drying air temperatures and microwave power level. The rate constant, $k$, which is a measure of the drying rate, significantly increased with drying air temperature resulting in substantial reduction in total drying time. Table 3 lists the model constants obtained by application of three equations to the experimental drying data. The drying constant $(k)$ for untreated sample of green bell pepper in HAD increased from 0.00578 to $0.00969 \mathrm{~m}^{-1}$ with the increase in drying air temperature from 60 to $80^{\circ} \mathrm{C}$. It can be seen from the Table 3 that $k$ values for VAM drying of green bell pepper were higher than HAD. In VAM drying, the value of $k$ increased as the microwave power and system vacuum increased. For a given microwave power level of $100 \mathrm{~W}$, the value of $k$ was found out to be $0.98034,1.1159$ and 2.1497 at 200, 400 and $600 \mathrm{~mm} \mathrm{Hg}$ respectively. The probable reason may be because higher microwave power and system vacuum helped in increasing the driving force of heat and mass transfer. The values for parameters ' $k$ ', ' $a$ ' and ' $c$ ' were in proximity to those reported in the literature for green bell pepper and other products (Arslan \& Ozcan, 2011; Di Scala \& Crapliste, 2008; Darvishi, Khoshtaghaza, Najafi, \& Nargesi, 2013).

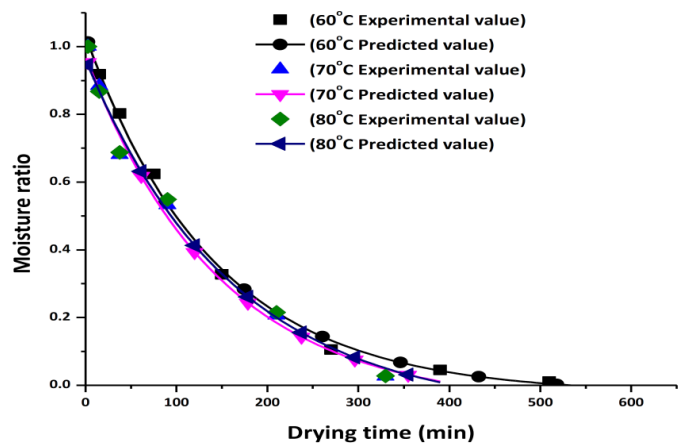

Figure 10: Logarithmic model curve for HAD at three different temperatures

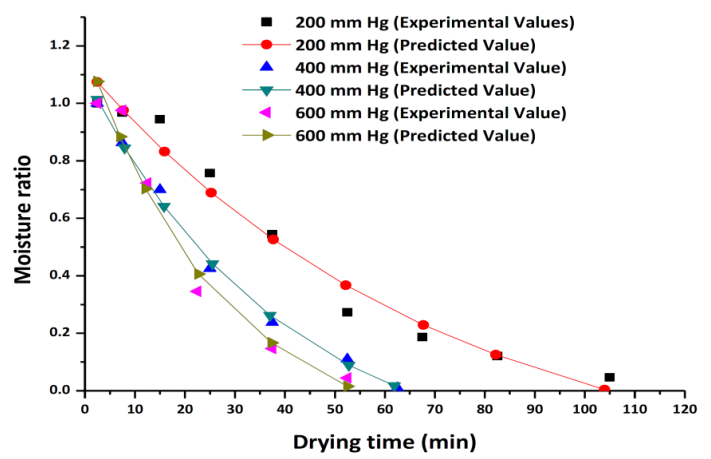

Figure 11: Logarithmic model curve for VAM drying at $200 \mathrm{~W}$

\subsection{Effect of moisture content on effective moisture diffusivity}

The estimated $D_{\text {eff }}$ values of bell pepper during HAD and VAM drying varied considerably with moisture content as can be seen from the graph between $D_{\text {eff }}$ and moisture content (Figures 12 and 13). For both HAD and VAM drying methods, the average $D_{\text {eff }}$ was calculated by taking the arithmetic mean of $D_{e f f}$ that were estimated at various levels of moisture contents 
$76 \mid$ Kumar and Shrivastava

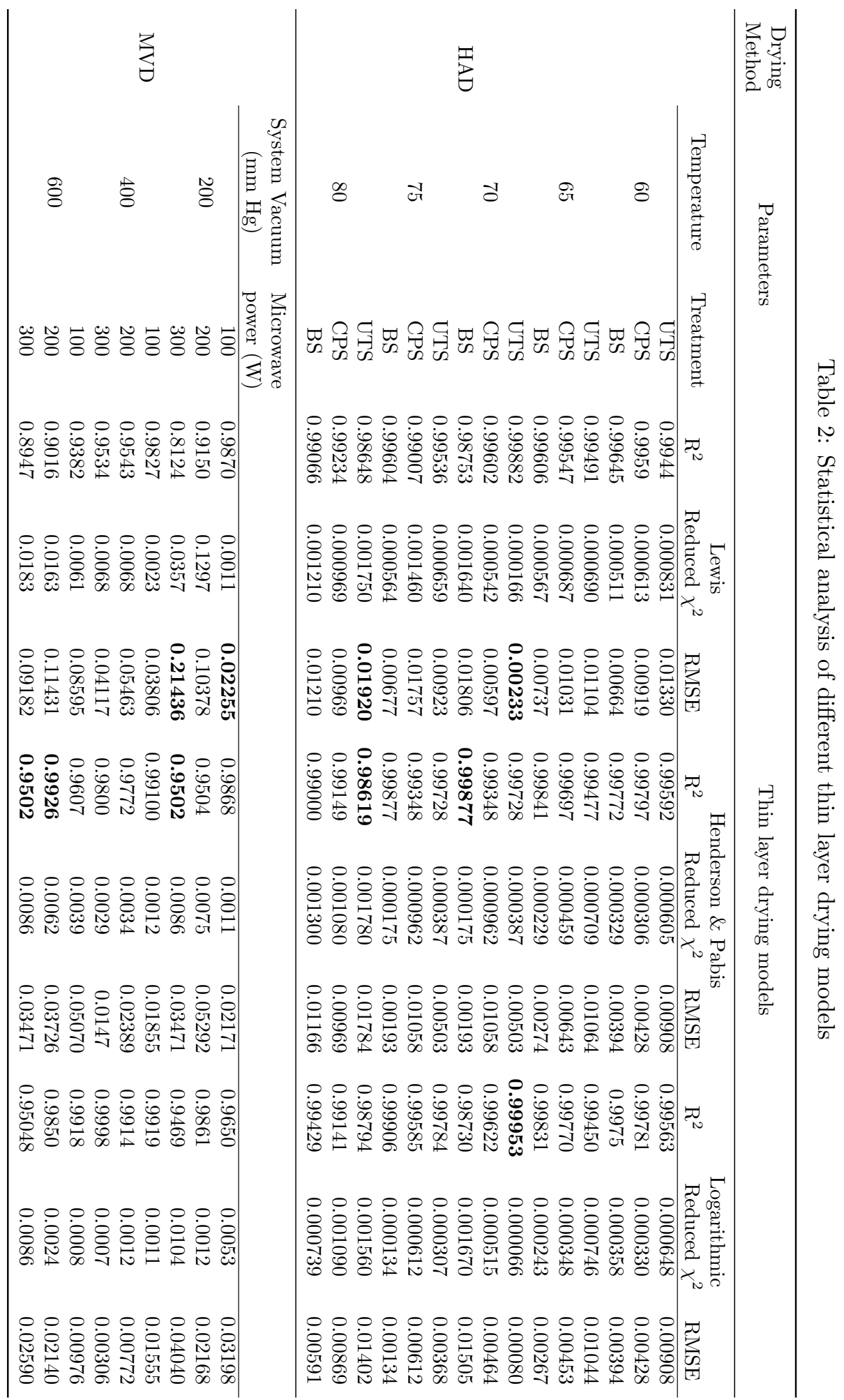

IJFS | April 2017 | Volume 6 | pages 67-81 


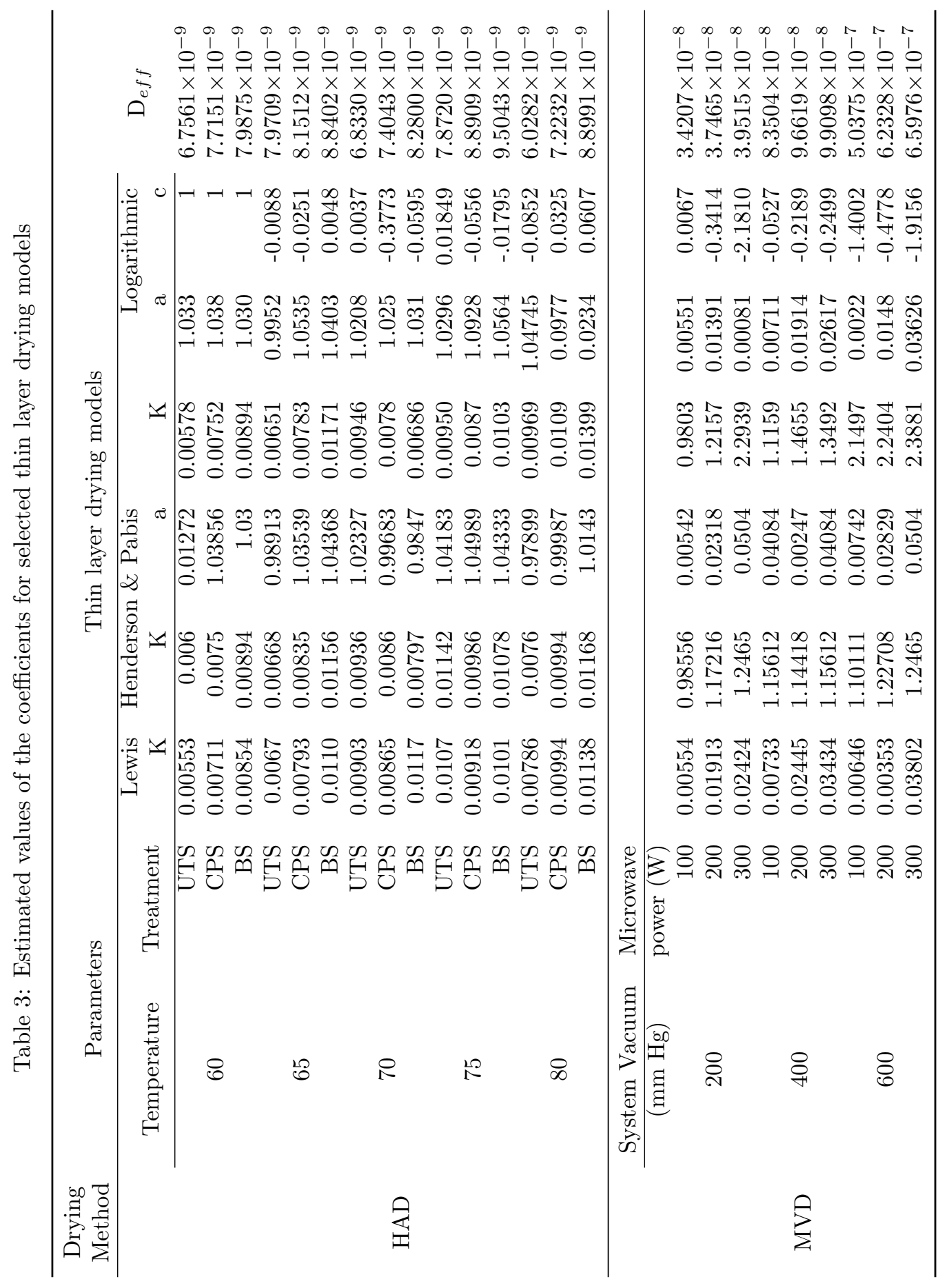


during drying. Average values of $D_{\text {eff }}$ at different temperature and microwave power are presented in Table 3. The maximum value of diffusivity was found to be $9.5043 \times 10^{-9}$ in the case of the blanched sample dried at $75^{\circ} \mathrm{C}$ air temperature and $6.5976 \times 10^{-7}$ at $300 \mathrm{~W}$ and $600 \mathrm{~mm} \mathrm{Hg}$ in VAM drying. It was evident from Figure 12 that $D_{\text {eff }}$ increased with a decrease in moisture content of the products. The possible reason for this kind of behaviour was that the initial sample temperature was less than drying air temperature at the beginning of the drying process. The temperature of the product increased gradually as moisture content decreased and hence the value of $D_{\text {eff }}$ increased, as mass diffusivity values have been reported to be a function of moisture content and temperature (Geankoplis, 2003). Hence in spite of a decrease in drying rate, the diffusivity value increased with the decrease in moisture content only because of the increase in product temperature.

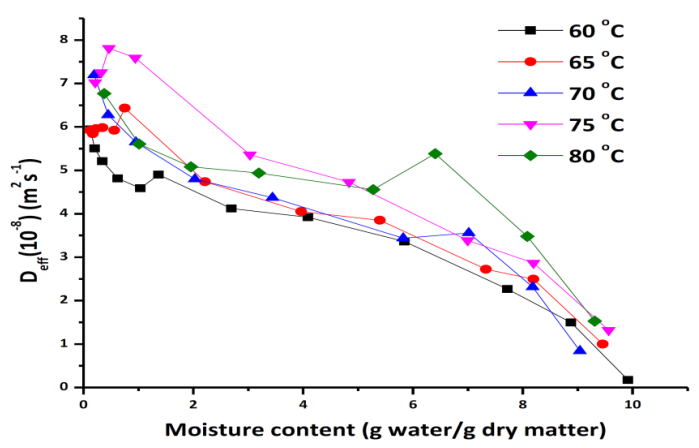

Figure 12: Variation in $D_{\text {eff }}$ with moisture content of chemically pretreated sample during hot air drying

\subsection{Activation energy}

The effect of temperature on the diffusivity was expressed by the Arrhenius equation, where the logarithm of the diffusivity exhibited a linear relationship against the reciprocal of the absolute temperature (Figure 14). In the case of HAD, the values of activation energy $E_{a}$ and $D_{0}$ were found out to be $43.38 \mathrm{kJmol}^{-1}$ and $7.730 \times 10^{-2}$,

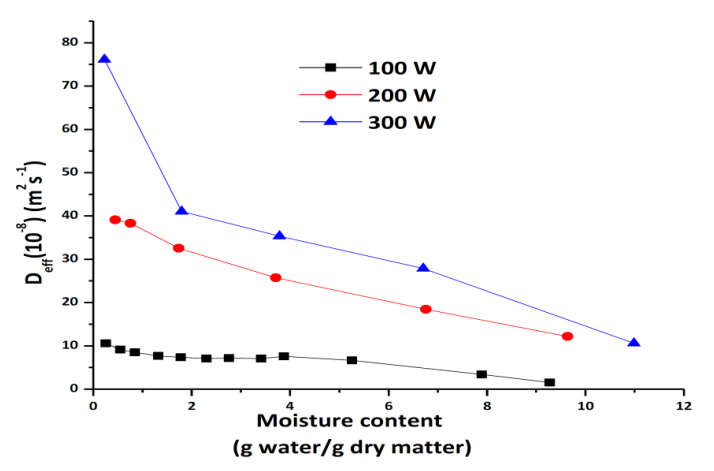

Figure 13: Variation in $D_{\text {eff }}$ with moisture content of green bell pepper samples at $400 \mathrm{~mm} \mathrm{Hg}$

respectively. The results were found to be similar to the work of Doymaz and Ismail (2010), and Taheri-Garavand, Rafiee, and Keyhani (2011).

In the VAM drying method, activation energy was calculated from the $\left(D_{\text {eff }}\right.$ vs. w/P) curve (Eq. 12). Based on statistical analysis and logarithmic model coefficients, $D_{0}$ and $E_{a}$ values were estimated as $0.2469 \mathrm{~min}^{-1}$ and $15.04 \mathrm{Wg}^{-1}$. The values of $D_{\text {eff }}$ were in the range found by other researchers (Arslan \& Ozcan, 2011; Di Scala \& Crapliste, 2008; Doymaz \& Ismail, 2010; Wang et al., 2007; Darvishi et al., 2013).

The activation energy was also calculated by an alternate method i.e. by calculating the coefficients for Eq. 13 from $k$ versus (w/P) curve, which yielded $k_{0}$ and $E_{a}$ values of $1 \times 10^{-6} \mathrm{~m}^{2} \mathrm{~s}^{-1}$ and $16.194 \mathrm{Wg}^{-1}$. The values of activation energy were comparable with the reported values of $14.194 \mathrm{Wg}^{-1}$ for green pepper (Darvishi et al., 2013), $16.674 \mathrm{Wg}^{-1}$ and $24.22 \mathrm{Wg}^{-1}$ for sweet and sour pomegranate (Minaei, Motevali, Ahmadi, \& Azizi, 2011), $5.54 \mathrm{Wg}^{-1}$ for Okra (Dadali et al., 2007).

Unlike conventional heating systems, microwaves penetrate food and expand heat throughout the material (Schiffmann, 1992). As microwaves penetrate food, a gradient is created whereby the moisture migrates towards the superficial layers of food and is simultaneously carried away by the vacuum. As a result, in VAM drying, less energy is required to facilitate diffusion of moisture from food, resulting in lowering of activation energy. Thus the activation energy required in 
VAM dryer was found to be lower than hot air dryer. These results were in agreement with the previous investigations done on the calculation of activation energy of green bell pepper. The lower activation energy in case of VAM drying of green bell pepper requires less energy and hence, is a cost and energy saving method.

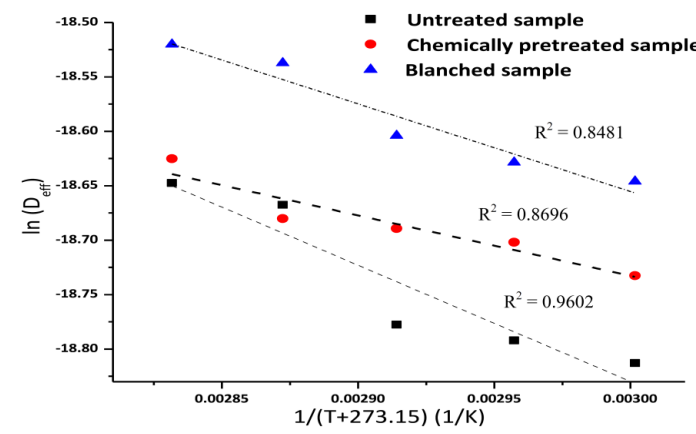

Figure 14: Arrhenius-type relationship between effective diffusivity and reciprocal absolute temperature for HAD samples

\section{Conclusions}

The data of weight loss of bell pepper samples with time were recorded in the HAD and VAM drying experiments, and they were converted into different drying parameters such as moisture content $(\mathrm{db})$, drying rate ( $\mathrm{g}$ water evaporated $\mathrm{g}$ dry matter $\left.{ }^{-1} \min ^{-1}\right)$, moisture ratio (MR), ln (MR), and effective moisture diffusivity $\left(\mathrm{ms}^{-2}\right)$ using standard methods and formula. VAM drying methods offered a maximum reduction of four to five times in drying time as compared to that in HAD. The final moisture content varied from 0.06 to $0.07 \mathrm{~kg}$ of water $\mathrm{kg}$ of dry matter ${ }^{-1}$. The drying time ranged from $660 \mathrm{~min}$ (untreated sample at $60{ }^{\circ} \mathrm{C}$ ) to $360 \mathrm{~min}$ (blanched sample at $80^{\circ} \mathrm{C}$ ) in the case of HAD and $75 \mathrm{~min}(300 \mathrm{~W})$ to $450 \mathrm{~min}(100 \mathrm{~W})$ in the case of VAM drying. The drying time decreased with increase in drying air temperature and power level. However, the effect of system pressure on drying time was not as significant as that of microwave power. The logarithmic equation best fitted the experimental drying data to describe the thin layer drying of green bell pepper. The values of activation energy $E_{a}$ were calculated to be $43.38 \mathrm{kJmol}^{-1}$ in the case of HAD and 15.04 and $16.194 \mathrm{Wg}^{-1}$ in the case of VAM dried sample. Thus vacuum assisted microwave drying yielded better dried green bell pepper with lower drying time, higher diffusivity value, and lower activation energy requirement.

\section{Acknowledgements}

This work was financially supported by Department of Biotechnology, Government of India. The support is gratefully appreciated.

\section{References}

Arslan, D. \& Ozcan, M. M. (2011). Dehydration of red bell-pepper (capsicum annuum 1.): change in drying behavior, colour and antioxidant content. Food and Bioproducts Processing, 89(C4), 504-513. doi:10.1016/ j.fbp.2010.09.009

Bhattacharya, M., Srivastav, P. P., \& Mishra, H. N. (2015). Thin-layer modeling of convective and microwave-convective drying of oyster mushroom (pleurotus ostreatus). Journal of Food Science and Technologymysore, 52(4), 2013-2022. doi:10.1007/ s13197-013-1209-2

Chauhan, A. K. S. \& Srivastava, A. K. (2009). Optimizing drying conditions for vacuum-assisted microwave drying of green peas (pisum sativum 1.) Drying Technology, 27(6), 761-769. doi:10 . 1080/ 07373930902828120

Cui, Z. W., Xu, S. Y., \& Sun, D. W. (2003). Dehydration of garlic slices by combined microwave-vacuum and air drying. Drying Technology, 21 (7), 1173-1184. doi:10.1081/ DRT-120023174

Dadali, G., Apar, D. K., \& Ozbek, B. (2007). Microwave drying kinetics of okra. Drying Technology, 25 (4-6), 917-924. doi:10.1080/ 07373930701372254

Darvishi, H., Khoshtaghaza, M. H., Najafi, G., \& Nargesi, F. (2013). Mathematical modeling of green pepper drying in microwave-convective dryer. Journal 
of Agricultural Science and Technology, 15(3), 457-465. Retrieved from http : / / jast . modares . ac . ir / article_4975_ 8f9d927bcae292dc5f1e5f15ca750036.pdf

Di Scala, K. \& Crapliste, G. (2008). Drying kinetics and quality changes during drying of red pepper. LWT-Food Science and Technology, 41(5), 789-795. doi:10.1016/j.lwt. 2007.06.007

Diamante, L. M. \& Munro, P. A. (1991). Mathematical-modeling of hot air drying of sweet-potato slices. International Journal of Food Science and Technology, 26(1), 99-109.

Doymaz, I. \& Ismail, O. (2010). Drying and rehydration behaviors of green bell peppers. Food Science and Biotechnology, 19(6), 1449-1455. doi:10.1007/s10068-010-0207-7

Geankoplis, C. (2003). Transport processes and separation process principles (includes unit operations) fourth edition (Fourth). Upper Saddle River, NJ, USA: Prentice Hall Press.

Giri, S. K. \& Prasad, S. (2007). Drying kinetics and rehydration characteristics of microwave-vacuum and convective hot-air dried mushrooms. Journal of Food Engineering, 78(2), 512-521. doi:10.1016/j . jfoodeng.2005.10.021

Govindarajan, V. S. \& Salzer, U. J. (1985). Capsicum-production, technology, chemistry, and quality part 1: history, botany, cultivation, and primary processing. $C R C$ Critical Reviews in Food Science and $\mathrm{Nu}$ trition, 22(2), 109-176. PMID: 3899517. doi:10.1080/10408398509527412

Guine, R. P. F. \& Fernandes, R. M. C. (2006). Analysis of the drying kinetics of chestnuts. Journal of Food Engineering, 76(3), 460467. doi:10.1016/j.jfoodeng.2005.04.063

Henderson, S. M. \& Pabis, S. (1961). Grain drying theory i. temperature effect on drying coefficient. Journal of Agricultural Engineering Research, 6(3), 169-174.

Jayaraman, K. S., Gopinathan, V. K., Pitchamuthu, P., \& Vijayaraghavan, P. K. (1982). The preparation of quickcooking dehydrated vegetables by high temperature short time pneumatic drying. International Journal of Food Sci- ence \& Technology, 17(6), 669-678. doi:10.1111/j.1365-2621.1982.tb00226.x

Khraisheh, M. A. M. (1996). Investigation and modelling of combined microwave and air drying. (Doctoral dissertation, Queen's University of Belfast).

Kiranoudis, C. T., Tsami, E., \& Maroulis, Z. B. (1997). Microwave vacuum drying kinetics of some fruits. Drying Technology, 15(10), 2421-2440. doi:10 . 1080 / 07373939708917368

Lewis, W. K. (1921). The rate of drying of solid materials. Journal of Industrial \& Engineering Chemistry, 13(5), 427-432. doi:10. 1021/ie50137a021. eprint: http://dx.doi. org/10.1021/ie50137a021

Lian, G., Harris, C. S., Evans, R., \& Warboys, M. (1997). Coupled heat and moisture transfer during microwave vacuum drying. Journal of Microwave Power and Electromagnetic Energy, 32(1), 34-44.

Minaei, S., Motevali, A., Ahmadi, E., \& Azizi, M. H. (2011). Mathematical models of drying pomegranate arils in vacuum and microwave dryers. Journal of agricultural Science and Technology, 14(2), 311-325.

Mudgett, R. E. (1990). Developments in microwave food-processing. In $\mathrm{H}$. G. Schwartzberg \& M. A. Rao (Eds.), Biotechnology and food process engineering (pp. 359-404). IFT BASIC SYMPOSIUM SERIES. Symp of the 49th annual meeting of the inst of food technologists : Advances in bio-process and food-process engineering, Chicago, IL, Jun 23-24, 1989.

Mujumdar, A. S. (1980). Advances in drying. CRC Press.

Saravacos, G. D. \& Maroulis, Z. B. (2001). Transport properties of foods. CRC Press.

Schiffmann, R. F. (1992). Microwave processing in the US food industry: Dielectric and ohmic sterilization. Food Technology, 46(12), 50-52.

Sharma, G. P. \& Prasad, S. (2001). Drying of garlic (Allium sativum) cloves by microwavehot air combination. Journal of Food Engineering, 50 (2), 99-105. doi:10.1016/S02608774(00)00200-4

Simal, S., Mulet, A., Tarrazo, J., \& Rossello, C. (1996). Drying models for green peas. Food 
VAM drying of green bell pepper $\mid 81$

Chemistry, 55(2), 121-128. doi:10.1016/ 0308-8146(95)00074-7

Taheri-Garavand, A., Rafiee, S., \& Keyhani, A. (2011). Study on effective moisture diffusivity, activation energy and mathematical modeling of thin layer drying kinetics of bell pepper. Australian Journal of Crop Science, 5(2), 128-131.

Toğrul, İ. T. \& Pehlivan, D. (2002). Mathematical modelling of solar drying of apricots in thin layers. Journal of Food Engineering, 55(3), 209-216. doi:10.1016/S02608774(02)00065-1

Tulek, Y. (2011). Drying kinetics of oyster mushroom (pleurotus ostreatus) in a convective hot air dryer. Journal of Agricultural Science and Technology, 13(5), 655-664.

Tunde-Akintunde, T. Y. \& Ogunlakin, G. O. (2011). Influence of drying conditions on the effective moisture diffusivity and energy requirements during the drying of pretreated and untreated pumpkin. Energy Conversion and Management, 52(2), 11071113. doi:10.1016/j.enconman.2010.09.005

Wang, Z., Sun, J., Liao, X., Chen, F., Zhao, G., $\mathrm{Wu}$, J., \& Hu, X. (2007). Mathematical modeling on hot air drying of thin layer apple pomace. Food Research International, 40(1), 39-46. doi:10.1016/j.foodres. 2006. 07.017

Wesley, B. J., Chakraverty, A., \& Sukumaran, C. R. (2002). Dehydration of chillies and their quality determination. The Andhra Agricultural Journal, 49(1\&2), 93-96.

Woodroof, J. (2012). Commercial fruit processing. Springer Science \& Business Media. doi:10.1007/978-94-011-7385-8 